\title{
Plastic Embolic Bead
}

National Cancer Institute

\section{Source}

National Cancer Institute. Plastic Embolic Bead. NCI Thesaurus. Code C97233.

An embolic bead that is made from a plastic-like resin or polymer. 